medRxiv preprint doi: https://doi.org/10.1101/2021.09.30.21264351; this version posted October 1, 2021. The copyright holder for this preprint (which was not certified by peer review) is the author/funder, who has granted medRxiv a license to display the preprint in perpetuity.

All rights reserved. No reuse allowed without permission.

\title{
Community social vulnerability and access to medications for opioid use disorder within the continental US: A cross-sectional study
}

\author{
Paul J. Joudrey, ${ }^{1}$ Marynia Kolak, ${ }^{2}$ Qinyun Lin, ${ }^{2}$ Susan Paykin, ${ }^{2}$ \\ Vidal Anguiano Jr, ${ }^{2}$ Emily A. Wang ${ }^{1}$ \\ 1) Program in Addiction Medicine, Department of Internal \\ Medicine, Yale School of Medicine, New Haven, CT \\ 2) Healthy Regions \& Policies Lab, Center for spatial Data \\ Science, University of Chicago, Chicago, IL
}

\section{Corresponding author}

Paul J. Joudrey, MD, MPH

Department of Internal Medicine, Yale School of Medicine

367 Cedar Street, Harkness Hall A

New Haven, CT 06520

$203-737-5357$

paul.joudrey@yale.edu

Word count: 3,709 


\section{Abstract}

The COVID-19 pandemic, like past natural disasters, was associated with significant disruptions in medications for opioid use disorder services and increased opioid overdose and mortality. We examined the association between community vulnerability to disasters and pandemics and geographic access to each of the three medications for opioid use disorder within the continental US and if this association was impacted by urban, suburban, or rural classification. We found communities with greater vulnerability did not have greater geographic access to medications for opioid use disorder and the mismatch between vulnerability and medication access was greatest in suburban communities. Rural communities had poor geographic access to all three medications regardless of vulnerability. Future disaster preparedness planning should include anticipation of access to medications for opioid use disorder and better match the location of services to communities with greater vulnerability to prevent inequities in opioid overdose deaths. 


\section{Introduction}

US opioid overdose deaths increased within both urban and rural communities and continue to rise in the context of the 2019 novel coronavirus (COVID-19) pandemic. $(1,2)$ Treatment with the three US Food and Drug Administration approved medications for opioid use disorder (MOUD), buprenorphine, methadone, and extended-release naltrexone, can reduce opioid overdose deaths, (3-5) but they are not equivalent or interchangeable. (6) Buprenorphine is a partial opioid agonist available within office-based settings via DATA 2000 waiver. $(6,7)$ Methadone is a full opioid agonist but can only be provisioned at federally certified opioid treatment programs (OTP). (6,7) Extended-release naltrexone is an opioid antagonist and is typically dispensed by a specialty pharmacy and administered by the prescriber. $(6,7)$ Given the differences in pharmacology and delivery, the three MOUD should be accessible in all communities to facilitate treatment individualization and maximization of treatment retention. (6) However, there is a shortage of MOUD services, disproportionately impacting rural communities and contributing to racial inequities in access. $(8,9)$ Most US patients with opioid use disorder (OUD) never initiate a MOUD. (6,10)

Evidence suggests COVID-19 and other recent natural disasters exacerbated the shortage of MOUD services(11-15) and were associated with increased opioid overdose and chronic disease mortality. $(2,12,14,16)$ All-cause mortality increased $62 \%$ in Puerto Rico following Hurricane Maria and around one third of 
excess deaths were attributable to healthcare service disruptions.(16) In the context of COVID-19, US opioid overdose deaths increased 29\% from November 2019 to November 2020.(2) Despite efforts to mitigate the impact of COVID-19 on MOUD services, such as increased telemedicine for OAT and relaxation of methadone take home dosing requirements, $(15,17)$ a reduction in locations accepting new methadone patients and long wait times to initiate a medication were observed during the pandemic. (15)

With the ongoing COVID-19 pandemic and the expected increased frequency of climate change related extreme weather events, $(18,19)$ it is important to examine how a community's ability to respond to natural disasters and infectious disease outbreaks is associated with current access to MOUD, especially given the already uneven access to the medications. The World Health Organization and the US Substance Abuse and Mental Health Services Administration (SAMHSA) have recommended state and local agencies develop disaster plans for patients receiving methadone and buprenorphine.(20-22) But no past studies have examined the relationship between access to each medication and a community's ability to respond to disaster or infectious disease outbreaks. Identifying communities with greater vulnerability to disasters and pandemics and low access to MOUD could inform interventions and policies aiming to expand MOUD access and mitigate future disparities in mortality. Therefore, we examined the association between social vulnerability and access to each of the three MOUDs within the continental US and 
medRxiv preprint doi: https://doi.org/10.1101/2021.09.30.21264351; this version posted October 1, 2021. The copyright holder for this preprint (which was not certified by peer review) is the author/funder, who has granted medRxiv a license to display the preprint in perpetuity.

All rights reserved. No reuse allowed without permission.

if this association was impacted by community urban-rural classification.

\section{Methods}

Study overview and data sources

We completed a cross-sectional geospatial analysis within the continental US. To measure a community's ability to respond to natural disasters and infectious disease outbreaks, we obtained 2018 census tract social vulnerability index (SVI) data from Centers for Disease Control and Prevention.(23) The SVI is a validated measure of community vulnerability to natural (e.g. hurricane or infectious disease) or human-caused stressors (e.g. chemical spill).(24) The SVI is derived from 15 US Census Bureau American Community Survey variables and measures overall vulnerability of a census tract and vulnerability across four specific themes: 1) Socioeconomic status (below poverty, unemployed, income, no high school diploma), 2) Household composition and disability (aged 65 or older, aged 17 or younger, older than age 5 with a disability, single-parent households), 3) Minority status and language (minority, speak English "less than well"), and 4) Housing type and transportation (multi-unit structures, mobile homes, crowding, no vehicle, group quarters such as worker dormitories, skilled nursing facilities, or college dorms). (23) The SVI assigns each tract a score based on percentile rank (scored 0 to 1 with 1 representing the highest vulnerability).(23) The SVI was found to predict disaster related property damage and fatalities over 
a 12-year period among 10 southeastern states and was included within the inter-agency US Climate Resilience Toolkit to facilitate disaster preparedness planning.(25) In the context of COVID-19, increasing SVI scores were associated with increased community COVID-19 cases and deaths and lower rates of COVID-19 vaccination. $(26-28)$

We measured geographic access to the three MOUD using the following data sources. The primary data source was the SAMHSA Behavioral Health Treatment Services Locator for all substance use treatment clinics providing methadone and extended-release naltrexone (derived from the 2019 National Survey of Substance Abuse Treatment Services) and DATA 2000 waiver buprenorphine providers. (29) Also, because extended-release naltrexone may be provisioned outside of substance use treatment clinics, we obtained location data on all clinicians registered with the pharmaceutical manufacturer as providing extended-release naltrexone from the "Find a treatment provider" website on August 29, 2020.(30)

To provide a comparison of accessing treatment services for another chronic disease necessitating thrice weekly visits, we obtained dialysis center location data from the Centers for Medicare and Medicaid Services' (CMS) Dialysis Facility Compare database on May 12, 2020.(31)

Study population

We included all zip code Tabulation Areas (ZCTA) within the continental US. Created by the US Census Bureau, ZCTAs are 
generalized aerial representations of populated US Postal Service ZIP Code service areas. ${ }^{28}$ We used ZCTAs because they are often the smallest geographic unit available to health researchers, in contrast to tract level which may show more neighborhood variation. We excluded Washington, D.C. ZCTAs because the travel cost matrix used for drive time estimation only included US states.

Dependent Variable

Our primary outcome was drive time in minutes from the population weighted center of the ZCTA to the ZCTA of the nearest treatment location for each treatment type: buprenorphine, methadone, extended-release naltrexone, and dialysis. We excluded treatment locations outside the continental US. There are a limited number of street address locations which cannot be assigned to a ZCTA, (32) and we excluded any treatment location without an assigned ZCTA. To calculate ZCTA access outcomes nationally, we generated an origin-destination matrix of travel times along the street network using Open source Routing Machine (OSRM) to ZCTAs within $100 \mathrm{~km} .(33)$ To calculate drive time to the nearest treatment location, we used the spatial_access Python package, (33) using the travel time matrix. For origin zCTAs also containing the treatment destination, the drive time was estimated as 0 minutes.

Secondary outcomes were the total number of treatment locations within or near a ZCTA and number of MOUD types (0 to 3 ). 
Treatment locations within a 30-minute drive time of the population weighted center of the ZCTA for each treatment type were tabulated with the spatial_access package. (33) We used a 30-minute drive time threshold to represent the number of services available in a ZCTA because 30 minutes is a widely accepted standard for acceptable geographic access for Medicaid beneficiaries and has been used to examine access to methadone for people with OUD and dialysis for people with end stage renal disease.(34-37) To account for differences in the size and age of the population at risk of OUD, we also created a count of treatment locations within a 30-minute drive time per 100,000 adults between ages 18 and 64 for each ZCTA based on the American Community Survey 2018 5-year estimate.

\section{Independent Variable}

Consistent with previous studies, (38) we converted census tract SVI scores into zip code-scale scores using the US Department of Housing and Urban Development U.S. Postal Services ZIP Code Crosswalk. (39) When a zip code spanned multiple census tracts, we calculated weighted average SVI scores using the ratio between the total addresses in each tract over the total addresses in the entire zip code area. (40) We matched all zip codes with SVI scores to their assigned ZCTAs.

\section{Covariates}

Covariates included zip codes classification by urbanicity. We obtained 2010 Rural-Urban Commuting Area (RUCA) codes for zip codes from the US Department of Agriculture and University of 
Washington Rural Health Research Center.(41) We classified zip codes as either urban (codes 1 and 1.1), suburban (2, 2.1, 4, and 4.1), or rural (all other codes) using RUCA codes. We modified the widely used University of Washington recommendations for RUCA urban-rural classification by first collapsing the large and small rural codes into one category and then identifying codes 3, 5.1, 7.1, 8.1, and 10.1 as rural instead of suburban. (42) This latter change was driven by observations suggesting the traditional University of Washington approach may overestimate urban and suburban areas. (43) We matched all zip codes assigned a RUCA code to their ZCTA. For analyses stratified by urban-rural classification, we excluded ZCTAs without an assigned RUCA code.

Spatial and Statistical Analysis

First, we identified the count of zCTAs, total population, total population between ages 18 and 64, and treatment locations within the continental US and the median SVI score among all ZCTAs and within each urban-rural strata. Then we used a Kruskal-Wallis test for comparisons of drive time to the four treatment types and for comparisons by urban-rural strata.

We created correlation matrices among all zCTAs and among each urban-rural strata, using spearman's rank correlation, to examine the relationship between overall SVI and each SVI theme and access to each treatment type. For each correlation matrix, we reversed the direction of the count of treatment locations within a 30-minute drive time so that the direction of 
correlation for these secondary outcomes were aligned with drive time (positive correlation with SVI meaning greater vulnerability was associated with longer drive time or less treatment locations). We used a Bonferroni correction for multiple comparisons. Given our large sample size, all hypothesis tests were two-sided with an alpha 0.001 . We reported correlations of magnitude between -0.09 and 0.09 as no correlation regardless of statistical significance. We completed our analyses in the $\mathrm{R}$ software environment (version 4.0.2). University of Chicago Institutional Review Board determined this study did not involve human subjects.

This study has several limitations. First, this study uses the general population between the ages of 18 to 64 to represent treatment need, and this may differ from the location of individuals with OUD. Second, our measures of geographic access to MOUD does not account for the capacity of treatment locations. However, our results are consistent with previous research utilizing a gravity model approach to examine the urban-rural associations between socioeconomic status and access to buprenorphine and methadone.(44) Gravity models aim to account for the capacity of treatment locations and the spatial demand for treatment services. However, gravity model approaches currently require a priori assumptions about the ability to travel for MOUD treatment and the capacity of MOUD treatment locations both of which will vary spatially. Third, our secondary outcomes used a 30-minute travel threshold which likely overestimates availability for people facing 
medRxiv preprint doi: https://doi.org/10.1101/2021.09.30.21264351; this version posted October 1, 2021. The copyright holder for this preprint (which was not certified by peer review) is the author/funder, who has granted medRxiv a license to display the preprint in perpetuity.

All rights reserved. No reuse allowed without permission.

transportation barriers. Fourth, our study does not account for mode of transportation (e.g. private vehicle, public bus, etc.) or the impact of traffic or weather. Fifth, because drive time was estimated as zero for zCTAs containing a treatment location, our results likely underestimate drive time, particularly in urban ZCTAs. However, our secondary outcome is not impacted by this limitation. Sixth, our analysis reflects ZCTA population averages and does not account for variation in social vulnerability within zCTAs nor does it represent individuallevel access. $(45,46)$ Finally, temporal change in vulnerability was beyond the scope of our cross-sectional study but is an important direction for future research.

\section{Results}

Among 32,604 ZCTAs within the continental US, we excluded 170 within Washington, D.C. For analyses stratified by urban-rural classification, we excluded 20 zCTAs without a RUCA code. Among ZCTAs with a RUCA code ( $\mathrm{n}=32,584), 10,657$ (33\%) were urban, 8,067 (25\%) were suburban, and 13,860 (43\%) were rural (appendix exhibit 1 and appendix exhibit 2). Of the over 198 million individuals between age 18 and 64 in ZCTAs with a RUCA code, 76\% lived in urban, 15\% lived in suburban, and 9\% lived in rural ZCTAs. Median overall and theme SVI scores increased (i.e. were more vulnerable) with increasing rural ZCTA classification except for vulnerability due to minority status and language which decreased with increasing rural ZCTA classification (appendix exhibit 3 ) . 
We matched all buprenorphine $(\mathrm{n}=51,191)$, methadone ( $\mathrm{n}=$ 1,442), extended-release naltrexone ( $\mathrm{n}=9,103)$, and dialysis ( $\mathrm{n}$ $=7,724)$ treatment locations to zCTAs. For analysis by urbanrural classification, we excluded 15 buprenorphine, 2 extendedrelease naltrexone, and 66 dialysis treatment locations because they resided within the 20 zCTAs without an assigned RUCA code. Among treatment locations assigned a RUCA code, 3,163 (6\%) of buprenorphine, 43 (3\%) of methadone, 820 (9\%) of extendedrelease naltrexone, and 656 (8\%) of dialysis locations were within rural ZCTAs.

Among all zCTAs, median drive time to the nearest treatment location was greatest for methadone (35 minutes) and shortest for buprenorphine (16 minutes; $p<0.001)$. Only the median drive time to buprenorphine was shorter than median drive time to dialysis (20 minutes). For all treatment types, median drive time increased with increasing rural ZCTA classification

(exhibit 1 and exhibit 2). Among all ZCTAs, the median count of treatment locations within a 30-minute drive time was greatest for buprenorphine (8) and lowest for methadone $(0 ; p<0.001)$. Among all zCTAs, the count of methadone and extended-release naltrexone treatment locations within 30 minutes was less than or equal to the count of dialysis centers. For all treatment types, the median count of treatment locations within a 30minute drive time decreased with increasing rural ZCTA classification. These results were unchanged upon accounting for the number of adults within zCTAs between the ages 18 and 64 . Among all zCTAs, 152,090,242 (77\%) adults ages 18 to 64 lived in 
a ZCTA with all three MOUD within a 30-minute drive (appendix exhibit 4 ).

Social vulnerability and treatment access

Among all zCTAs, greater overall social vulnerability was not associated with greater access (shorter drive times and more available treatment locations) to MOUD. Greater overall social vulnerability was correlated with both longer drive times and less available treatment locations for methadone (correlation 0.10 for drive time and 0.11 for available locations, $p<0.001$ ). Among all ZCTAs, greater vulnerability due to minority status and language was correlated with greater access to MOUD (correlations between -0.30 and $-0.41, p<0.001$ ). There was no correlation or a correlation with less access to MOUD for vulnerability due to socioeconomic status (correlations 0.10 to $0.23, p<0.001)$, household composition and disability (correlations 0.25 to $0.39, p<0.001$ ), and housing type and transportation (correlations -0.03 to $0.10, p<0.001$ ) (exhibit 3) .

The association between social vulnerability and access to all three types of MOUD varied depending on urban-rural classification. Among rural ZCTAs, increasing overall social vulnerability was correlated with shorter drive times to buprenorphine (correlation $-0.10, p<0.001$ ) but overall vulnerability was not correlated with other measures of access to MOUD. Vulnerability by theme was not correlated with access among rural zCTAs, except vulnerability due to socioeconomic 
status and shorter drive time to buprenorphine (correlation $0.13, p<0.001)$ and vulnerability due to minority status and language and longer drive time and less available treatment locations for extended-release naltrexone (correlation 0.16 for drive time and 0.15 for available locations, $p<0.001$ ). While drive time to treatment services largely did not vary by SVI among rural ZCTAs, median drive times were longer in rural ZCTAs as compared with suburban and urban ZCTAs, including among rural ZCTAs in the highest quartile of SVI (Exhibit 3).

Among suburban zCTAs, greater overall vulnerability was correlated (correlations 0.12 to 0.29 , p<0.001) with both longer drive times and less available locations for all MOUD except drive time to buprenorphine (no correlation). Greater vulnerability due to socioeconomic status, household composition and disability, and housing type and transportation was correlated with both longer drive times and less available locations (correlations 0.13 to $0.30, p<0.001$ ), except for drive time to buprenorphine for all themes and drive time to extendedrelease naltrexone for vulnerability due to housing type and transportation. Among suburban ZCTAs, the median drive time to methadone increased from the lowest quartile of vulnerability to the highest quartile for socioeconomic status (32 to 47 minutes), household composition and disability (33 to 45 minutes), and housing type and transportation (35 to 45 minutes) (Exhibit 4 ). 
Among urban zCTAs, greater overall vulnerability was correlated (correlations -0.29 to $-0.10, p<0.001$ ) with shorter drive times for all MOUD but was not correlated with available treatment locations. Greater vulnerability due to minority status and language was correlated with shorter drive times and more available locations for MOUD (correlations -0.39 to -0.24, $p<0.001)$

Similar to geographic access to MOUD, among all ZCTAs, overall social vulnerability was not associated with greater access to dialysis for ESRD. Greater vulnerability due to household composition and disability was associated with less access to dialysis (correlations 0.23 for drive time 0.35 for available locations, p<0.001), while vulnerability due to minority status and language was associated with greater access (correlations -0.41 for drive time and -0.43 for available locations, p<0.001). Upon stratifying zCTAs by rural-urban status, within rural ZCTAs there was no correlation between overall social vulnerability and access to dialysis. Among suburban zCTAs, greater overall vulnerability was associated with shorter drive times and but less available dialysis locations (correlation = 0.10 and 0.12 , respectively, $p<0.001)$. Among urban ZCTAs, greater overall vulnerability was associated with shorter drive time times and more available treatment locations (correlation = -0.30 for drive time and -0.10 available locations, $p<0.001$ ). 


\section{Discussion}

In this cross-sectional geospatial analysis within the continental US, zip codes with greater social vulnerability did not have greater geographic access to each of the three MOUD, showing the degree to which the US falls short of ensuring equitable access to all MOUD, especially during natural disasters. Consistent with an emerging "opioid treatment desert" literature, (47) nearly one quarter of the continental US population live in zip codes without access to all three MOUD when using a conservative 30 minute travel threshold. We build upon past work by showing that urban-rural inequities were present for all measures of access to buprenorphine and methadone, as well as extended-release naltrexone, including drive time, count of nearby locations, and count of locations per population at risk. $(8,44,48)$ Drive times were significantly longer for methadone and extended-release naltrexone relative to dialysis centers, despite the prevalence of OUD being greater than ESRD. $(8,49,50)$

A novel finding of this study is that the mismatch between overall social vulnerability and the location of MOUD services was greatest in suburban zip codes as compared to rural and urban zip codes and does not exist for people with end stage renal disease. In examining the specific domains of social vulnerability, living in suburban communities with lower socioeconomic status or in households with more children, seniors, or individuals with disabilities was associated with less geographic access to methadone and extended-release 
naltrexone. And in contrast, geographic access was largely not associated with social vulnerability in rural zip codes because geographic access to MOUD was uniformly poor. Living in urban zip codes with greater social vulnerability due to higher proportion of residents of racial and ethnic minority status and non-English speakers was associated with greater geographic access to MOUD, suggesting that geographic access may not be as important of a barrier to MOUD treatment in these communities. One important caveat is that geography is just one dimension of access; (51) MOUD access is also impacted by stigma, affordability, accommodation, capacity, and more, and future research should examine the interaction of these factors with geographic access in vulnerable communities.

We improve upon previous research by utilizing two measures of small area (zip code tabulation area) geographic access (drive time and count of near locations) to all three types of MOUD, while incorporating two sources of extended-release naltrexone location data. Our results are consistent with previous research showing communities with lower socioeconomic status have less geographic access to methadone and buprenorphine, (44) and we extend these findings to extended-release naltrexone. By examining the four SVI themes, we find that communities vulnerable due to housing type and transportation also do not have greater geographic access to MOUD and may experience increased mortality during natural disasters and pandemics. While this was also true for vulnerability due to households with children, the elderly and the disabled, its relevance for 
OUD is less clear because the prevalence of OUD is both lower (i.e. elderly) and higher (i.e. individuals with disabilities preventing entry into the workforce) among subpopulations within this theme.

Our results call into question current disaster preparedness of OUD services and indicate the need to develop proactive measures to increase services within communities with greater vulnerability in the event of a disaster. Expanding OUD services is especially important in vulnerable suburban areas and across rural communities. Methadone should be a priority for innovation given it was the greatest barrier to ensuring access to each MOUD in all communities. Continuing changes in MOUD services during COVID-19, such as telehealth for opioid agonist treatment and increased methadone take home allowances, present opportunities to modify the geographic reach of services.(52) Further, reducing restrictions on medication units (OTP affiliated satellite locations for methadone administration and dispensing) and the recent end to the moratorium on new mobile methadone vans may also mitigate urban-rural inequalities and increase MOUD services within vulnerable communities if strategically implemented. $(34,53)$ Lastly, allowing methadone treatment outside of OTPs could greatly expand access, but office-based methadone would require federal and state regulatory changes for wide spread adoption. $(54,55)$ Currently, SAMHSA, the Drug Enforcement Agency, and state Opioid Treatment Authorities disaster planning for methadone treatment prioritize coordination among existing OTPs.(56) But coordination among 
OTPs alone in event of a disaster has been insufficient to ensure access to methadone, (15) especially in communities without a nearby OTP or alternate OTP. Canada increased the flexibility of its federal and provincial methadone regulations, including allowing methadone in office-based settings and medication dispensation within pharmacies, resulting in an expansion of methadone treatment services.(57) More flexible methadone regulation at the federal and state level within the US is likely required if the identified inequities in disaster preparedness are to be mitigated.

In conclusion, zip codes within the continental us with greater social vulnerability did not have greater geographic access to buprenorphine, methadone, or extended-release naltrexone. The mismatch between social vulnerability and the location of MOUD services was greatest in suburban zip codes, but rural zip codes had longer drive times to all three MOUD regardless of vulnerability. MOUD policy and delivery innovations need to address urban-rural inequities and better match the location of services to communities with greater social vulnerability to prevent inequities in opioid overdose deaths during future natural disasters.

\section{ACKNOWLEDGMENTS :}

We would like to thank Moksha Menghaney for assistant managing the SAMHSA data and Nathan Kim for his assistant obtaining the data on extended-release naltrexone. 
medRxiv preprint doi: https://doi.org/10.1101/2021.09.30.21264351; this version posted October 1, 2021. The copyright holder for this preprint (which was not certified by peer review) is the author/funder, who has granted medRxiv a license to display the preprint in perpetuity. All rights reserved. No reuse allowed without permission.

\section{References}

1. Hedegaard H, Spencer MR. Urban-Rural Differences in Drug Overdose Death Rates, 1999-2019. NCHS Data Brief. 2021;(403):1-8.

2. National Center for Health Statistics. Vital Statistics Rapid Release - Provisional Drug Overdose Data [Internet]. 2021 [cited 2021 Jun 22]. Available from: https://www.cdc.gov/nchs/nvss/vsrr/drug-overdose-data.htm

3. Mattick RP, Breen C, Kimber J, Davoli M. Buprenorphine maintenance versus placebo or methadone maintenance for opioid dependence. Cochrane database of systematic reviews. 2014;(2).

4. Lee JD, Friedmann PD, Kinlock TW, Nunes EV, Boney TY, Hoskinson Jr RA, et al. Extended-release naltrexone to prevent opioid relapse in criminal justice offenders. New England Journal of Medicine. 2016;374(13):1232-42.

5. Kelty E, Hulse G. Fatal and non-fatal opioid overdose in opioid dependent patients treated with methadone, buprenorphine or implant naltrexone. International Journal of Drug Policy. 2017 Aug 1;46:54-60.

6. Leshner Al, Mancher M. Medications for Opioid Use Disorder Save Lives. National Academies of Sciences, Enginneering, and Medicine. 2019;

7. McCarty D, Priest KC, Korthuis PT. Treatment and Prevention of Opioid Use Disorder: Challenges and Opportunities. Annual Review of Public Health. 2018;39(1):525-41.

8. Joudrey PJ, Edelman EJ, Wang EA. Drive times to opioid treatment programs in urban and rural counties in 5 US states. Jama. 2019;322(13):1310-2.

9. Goedel WC, Shapiro A, Cerdá M, Tsai JW, Hadland SE, Marshall BDL. Association of Racial/Ethnic Segregation With Treatment Capacity for Opioid Use Disorder in Counties in the United States. JAMA Netw Open. 2020 Apr 1;3(4):e203711e203711.

10. Blanco C, Volkow ND. Management of opioid use disorder in the USA: present status and future directions. The Lancet. 2019 Apr 27;393(10182):1760-72.

11. Hunter SB, Dopp AR, Ober AJ, Uscher-Pines L. Clinician perspectives on methadone service delivery and the use of telemedicine during the COVID-19 pandemic: A qualitative study. Journal of Substance Abuse Treatment. 2021 May 1;124:108288.

12. Gelpí-Acosta C, Rodríguez-Díaz CE, Aponte-Meléndez Y, Abadie R. Puerto Rican Syndemics: Opiates, Overdoses, HIV, and the Hepatitis C Virus in a Context of Ongoing Crises. Am J Public Health. 2020 Jan 8;110(2):176-7. 
medRxiv preprint doi: https://doi.org/10.1101/2021.09.30.21264351; this version posted October 1, 2021. The copyright holder for this preprint (which was not certified by peer review) is the author/funder, who has granted medRxiv a license to display the preprint in perpetuity. All rights reserved. No reuse allowed without permission.

13. Pouget ER, Sandoval M, Nikolopoulos GK, Friedman SR. Immediate impact of Hurricane Sandy on people who inject drugs in New York City. Substance use \& misuse. 2015;50(7):878-84.

14. Abadie R, Gelpi-Acosta C, Aquino-Ruiz F, Aponte-Melendez Y. COVID-19 risks among people who inject drugs in Puerto Rico. The International Journal on Drug Policy. 2020;

15. Joudrey PJ, Adams ZM, Bach P, Van Buren S, Chaiton JA, Ehrenfeld L, et al. Methadone Access for Opioid Use Disorder During the COVID-19 Pandemic Within the United States and Canada. JAMA Network Open. 2021 Jul 23;4(7):e2118223e2118223.

16. Kishore N, Marqués D, Mahmud A, Kiang MV, Rodriguez I, Fuller A, et al. Mortality in Puerto Rico after Hurricane Maria. New England Journal of Medicine. $2018 \mathrm{Jul}$ $12 ; 379(2): 162-70$.

17. Amram O, Amiri S, Thorn EL, Lutz R, Joudrey PJ. Changes in methadone takehome dosing before and after COVID-19. Journal of Substance Abuse Treatment. 2021 Jun 24;108552.

18. Hoogewind KA, Baldwin ME, Trapp RJ. The Impact of Climate Change on Hazardous Convective Weather in the United States: Insight from High-Resolution Dynamical Downscaling. Journal of Climate. 2017 Dec 15;30(24):10081-100.

19. Cohen J, Pfeiffer K, Francis JA. Warm Arctic episodes linked with increased frequency of extreme winter weather in the United States. Nature Communications. 2018 Mar 13;9(1):869.

20. WHO. Initiative on Building Climate Resilient and Environmentally Sustainabile Health Systems [Internet]. World Health Organization; 2020. Available from: https://cdn.who.int/media/docs/default-source/climate-change/who-initiative-onclimate-resilient-health-systems.pdf?sfvrsn=73bdfd15_5

21. WHO. Second Global Conference Health and Climate [Internet]. World Health Organization; 2016. Available from: https://cdn.who.int/media/docs/defaultsource/climate-change/action-agenda---2nd-global-conference-on-health-andclimate-change.pdf?sfvrsn=a2cad76f_0

22. SAMHSA. TAP 34 Disaster Planning Handbook for Behavioral Health Service Programs [Internet]. SAMHSA; 2021. Available from: https://store.samhsa.gov/sites/default/files/SAMHSA_Digital_Download/pep21-0201-001.pdf

23. Agency for Toxic Substances and Disease Registry. CDC's Social Vulnerability Index [Internet]. Place and Health. 2021 [cited 2021 Mar 10]. Available from: https://www.atsdr.cdc.gov/placeandhealth/svi/index.html 
medRxiv preprint doi: https://doi.org/10.1101/2021.09.30.21264351; this version posted October 1, 2021. The copyright holder for this preprint (which was not certified by peer review) is the author/funder, who has granted medRxiv a license to display the preprint in perpetuity. All rights reserved. No reuse allowed without permission.

24. Bakkensen LA, Fox-Lent C, Read LK, Linkov I. Validating resilience and vulnerability indices in the context of natural disasters. Risk analysis. 2017;37(5):982-1004.

25. NOAA's Climate Program Office. US Climate Resilience Toolkit [Internet]. 2021. Available from: https://toolkit.climate.gov/tool/social-vulnerability-index

26. Khazanchi R, Beiter ER, Gondi S, Beckman AL, Bilinski A, Ganguli I. County-Level Association of Social Vulnerability with COVID-19 Cases and Deaths in the USA.J GEN INTERN MED. 2020 Sep 1;35(9):2784-7.

27. Karaye IM, Horney JA. The Impact of Social Vulnerability on COVID-19 in the U.S.: An Analysis of Spatially Varying Relationships. American Journal of Preventive Medicine. 2020 Sep 1;59(3):317-25.

28. Hughes MM, Wang A, Grossman MK, Pun E, Whiteman A, Deng L, et al. CountyLevel COVID-19 Vaccination Coverage and Social Vulnerability - United States, December 14, 2020-March 1, 2021. MMWR Morb Mortal Wkly Rep. 2021 Mar $26 ; 70(12): 431-6$.

29. SAMHSA. Behavioral Health Treatment Services Locator [Internet]. [cited 2020 Aug 27]. Available from: https://findtreatment.samhsa.gov/

30. Alkermes. Find a treatment provider [Internet]. Find a Vivitrol provider. [cited 2021 Mar 10]. Available from: https://www.vivitrol.com/find-a-treatment-provider

31. The Centers for Medicare \& Medicaid Services. Dialysis facilities [Internet]. CMS.gov. [cited 2021 Apr 15]. Available from: https://data.cms.gov/providerdata/topics/dialysis-facilities

32. United States Census Bureau. ZIP Code Tabulation Areas (ZCTAs) [Internet]. The United States Census Bureau. [cited 2021 Mar 26]. Available from: https://www.census.gov/programs-surveys/geography/guidance/geoareas/zctas.html

33. Github. GeoDaCenter/spatial_access [Internet]. 2021. Available from: https://github.com/GeoDaCenter/spatial_access

34. Iloglu S, Joudrey PJ, Wang EA, Thornhill TA, Gonsalves G. Expanding access to methadone treatment in Ohio through federally qualified health centers and a chain pharmacy: A geospatial modeling analysis. Drug and Alcohol Dependence. 2021 Mar 1;220:108534.

35. Stephens JM, Brotherton S, Dunning SC, Emerson LC, Gilbertson DT, Harrison DJ, et al. Geographic disparities in patient travel for dialysis in the United States. The Journal of Rural Health. 2013;29(4):339-48. 
medRxiv preprint doi: https://doi.org/10.1101/2021.09.30.21264351; this version posted October 1, 2021. The copyright holder for this preprint (which was not certified by peer review) is the author/funder, who has granted medRxiv a license to display the preprint in perpetuity. All rights reserved. No reuse allowed without permission.

36. Moist LM, Bragg-Gresham JL, Pisoni RL, Saran R, Akiba T, Jacobson SH, et al. Travel time to dialysis as a predictor of health-related quality of life, adherence, and mortality: the Dialysis Outcomes and Practice Patterns Study (DOPPS). American Journal of Kidney Diseases. 2008;51(4):641-50.

37. Murrin S. State Standards for Access to Care in Medicaid Managed Care [Internet]. Department of Health and Human Services; 2014. Available from: https://oig.hhs.gov/oei/reports/oei-02-11-00320.pdf

38. Zottarelli LK, Sharif HO, Xu X, Sunil TS. Effects of social vulnerability and heat index on emergency medical service incidents in San Antonio, Texas, in 2018. J Epidemiol Community Health. 2021 Mar 1;75(3):271-6.

39. Office of Policy Development, and Research. HUD USPS ZIP Code Crosswalk Files | HUD USER [Internet]. [cited 2021 May 19]. Available from: https://www.huduser.gov/portal/datasets/usps_crosswalk.html

40. Goodchild MF, Anselin L, Deichmann U. A framework for the areal interpolation of socioeconomic data. Environment and planning A. 1993;25(3):383-97.

41. US Department of Agriculture. Rural-Urban Commuting Area Codes [Internet]. Rural-Urban Commuting Area Codes. [cited 2021 Mar 10]. Available from: https://www.ers.usda.gov/data-products/rural-urban-commuting-area-codes.aspx

42. Morrill R, Cromartie J, Hart G. Metropolitan, urban, and rural commuting areas: toward a better depiction of the United States settlement system. Urban geography. 1999;20(8):727-48.

43. West AN, Lee RE, Shambaugh-Miller MD, Bair BD, Mueller KJ, Lilly RS, et al. Defining "Rural” for Veterans' Health Care Planning. The Journal of Rural Health. 2010;26(4):301-9.

44. Amiri S, McDonell MG, Denney JT, Buchwald D, Amram O. Disparities in Access to Opioid Treatment Programs and Office-Based Buprenorphine Treatment Across the Rural-Urban and Area Deprivation Continua: A US Nationwide Small Area Analysis. Value in Health. 2021 Feb 1;24(2):188-95.

45. Wong DW. The modifiable areal unit problem (MAUP). In: WorldMinds: Geographical perspectives on 100 problems. Springer; 2004. p. 571-5.

46. Piantadosi S, Byar DP, Green SB. The ecological fallacy. American journal of epidemiology. 1988;127(5):893-904.

47. Hyder A, Lee J, Dundon A, Southerland LT, All D, Hammond G, et al. Opioid Treatment Deserts: Concept development and application in a US Midwestern urban county. PLOS ONE. 2021 May 12;16(5):e0250324. 
medRxiv preprint doi: https://doi.org/10.1101/2021.09.30.21264351; this version posted October 1, 2021. The copyright holder for this preprint (which was not certified by peer review) is the author/funder, who has granted medRxiv a license to display the preprint in perpetuity. All rights reserved. No reuse allowed without permission.

48. Langabeer JR, Stotts AL, Cortez A, Tortolero G, Champagne-Langabeer T. Geographic proximity to buprenorphine treatment providers in the U.S. Drug and Alcohol Dependence. 2020 Aug 1;213:108131.

49. Centers for Disease Control and Prevention. Chronic Kidney Disease in the United States, 2021 [Internet]. US Department of Health and Human Services; 2021.

Available from: https://www.cdc.gov/kidneydisease/pdf/Chronic-Kidney-Disease-inthe-US-2021-h.pdf

50. Center for Behavioral Health Statistics and Quality (CBHSQ). 2017 National Survey on Drug Use and Health: Detailed Tables. [Internet]. Substance Abuse and Mental Health Services Administration; 2018. Available from: https://www.samhsa.gov/data/sites/default/files/cbhsqreports/NSDUHDetailedTabs2017/NSDUHDetailedTabs2017.pdf

51. Penchansky R, Thomas JW. The concept of access: definition and relationship to consumer satisfaction. Medical care. 1981;127-40.

52. Davis CS, Samuels EA. Opioid Policy Changes During the COVID-19 Pandemic and Beyond. J Addict Med [Internet]. 2020 May 20 [cited 2020 Nov 12]; Available from: https://www.ncbi.nlm.nih.gov/pmc/articles/PMC7273953/

53. Knopf A. DEA proposal for mobile methadone finally released. Alcoholism \& Drug Abuse Weekly. 2020;32(10):3-4.

54. Samet JH, Botticelli M, Bharel M. Methadone in Primary Care-One Small Step for Congress, One Giant Leap for Addiction Treatment. New England Journal of Medicine. 2018;379(1):7-8.

55. Joudrey PJ, Edelman EJ, Wang EA. Methadone for Opioid Use DisorderDecades of Effectiveness but Still Miles Away in the US. JAMA Psychiatry [Internet]. 2020 Jul 15 [cited 2020 Aug 13]; Available from: https://jamanetwork.com/journals/jamapsychiatry/fullarticle/2768023

56. Elliott L, Benoit E, Matusow H, Rosenblum A. Disaster preparedness among opioid treatment programs: Policy recommendations from state opioid treatment authorities. International Journal of Disaster Risk Reduction. 2017 Aug 1;23:152-9.

57. Kurdyak P, Jacob B, Zaheer J, Fischer B. Patterns of methadone maintenance treatment provision in Ontario: Policy success or pendulum excess? Can Fam Physician. 2018;64(2):e95-103. 
Exhibit 1. Measure of Access to Medications for Opioid Use Disorder among ZCTAs within the Continental US

\begin{tabular}{|c|c|c|c|c|c|c|}
\hline Variable & $\mathbf{N}$ & $\begin{array}{c}\text { Overall, } \mathbf{N}= \\
32,5841\end{array}$ & Rural, $\mathbf{N}=13,860^{1}$ & Suburban, $\mathbf{N}=8,067^{1}$ & Urban, $\mathbf{N}=10,657^{1}$ & $\begin{array}{c}p- \\
\text { value }^{2}\end{array}$ \\
\hline Time (Methadone) & 29,379 & $35.00(16.00,60.00)$ & $62.00(44.00,84.00)$ & $39.00(27.00,54.00)$ & $13.00(7.00,20.00)$ & $<0.001$ \\
\hline Time (Naltrexone) & 32,143 & $22.00(9.00,40.00)$ & $38.00(23.00,59.00)$ & $25.00(16.00,37.00)$ & $7.00(0.00,12.00)$ & $<0.001$ \\
\hline Time (Dialysis) & 32,456 & $20.00(8.00,34.00)$ & $33.00(22.00,49.00)$ & $22.00(15.00,32.00)$ & $6.00(0.00,11.00)$ & $<0.001$ \\
\hline Time (Buprenorphine) & 32,557 & $16.00(0.00,30.00)$ & $28.00(17.00,43.00)$ & $19.00(10.00,28.00)$ & $0.00(0.00,7.00)$ & $<0.001$ \\
\hline count (Methadone) & 32,584 & $0.00(0.00,2.00)$ & $0.00(0.00,0.00)$ & $0.00(0.00,1.00)$ & $3.00(1.00,8.00)$ & $<0.001$ \\
\hline count (Naltrexone) & 32,584 & $2.00(0.00,10.00)$ & $0.00(0.00,1.00)$ & $1.00(0.00,4.00)$ & $20.00(8.00,42.00)$ & $<0.001$ \\
\hline count (Dialysis) & 32,584 & $2.00(0.00,8.00)$ & $0.00(0.00,1.00)$ & $2.00(0.00,3.00)$ & $16.00(7.00,36.00)$ & $<0.001$ \\
\hline count (Buprenorphine) & 32,558 & $8.00(1.00,53.00)$ & $1.00(0.00,5.00)$ & $6.00(1.00,19.00)$ & $117.00(43.00,269.00)$ & $<0.001$ \\
\hline $\begin{array}{l}\text { count (Methadone) per } \\
100 \mathrm{~K}\end{array}$ & 32,360 & $0.00(0.00,30.81)$ & $0.00(0.00,0.00)$ & $0.00(0.00,20.29)$ & $31.65(10.88,99.26)$ & $<0.001$ \\
\hline $\begin{array}{l}\text { count (Naltrexone) per } \\
100 \mathrm{~K}\end{array}$ & 32,424 & $61.51(0.00,302.00)$ & $0.00(0.00,117.92)$ & $43.73(0.00,272.48)$ & $201.56(72.35,544.08)$ & $<0.001$ \\
\hline $\begin{array}{l}\text { count (Dialysis) per } \\
100 \mathrm{~K}\end{array}$ & 32,442 & $69.41(0.00,253.49)$ & $0.00(0.00,127.71)$ & $61.96(0.00,241.18)$ & $162.71(66.93,427.03)$ & $<0.001$ \\
\hline $\begin{array}{l}\text { count (Buprenorphine) } \\
\text { per } 100 \mathrm{~K}\end{array}$ & 32,444 & $\begin{array}{c}378.79(24.27 \\
1,619.43)\end{array}$ & $78.22(0.00,587.15)$ & $\begin{array}{c}286.74(31.99 \\
1,304.27)\end{array}$ & $\begin{array}{c}1,211.60(441.48 \\
3,468.37)\end{array}$ & $<0.001$ \\
\hline
\end{tabular}

${ }^{1}$ Median (IQR). ${ }^{2}$ Kruskal-Wallis rank sum test.

Source: The primary data source was the SAMHSA Behavioral Health Treatment Services Locator for all substance use treatment clinics providing methadone and extended-release naltrexone (derived from the 2019 National Survey of Substance Abuse Treatment Services) and DATA 2000 waiver buprenorphine providers.(29) We also obtained location data on all clinicians registered with the pharmaceutical manufacturer as providing extendedrelease naltrexone from the "Find a treatment provider" website on August 29, 2020.(30) 
medRxiv preprint doi: https://doi.org/10.1101/2021.09.30.21264351; this version posted October 1, 2021. The copyright holder for this preprint (which was not certified by peer review) is the author/funder, who has granted medRxiv a license to display the preprint in perpetuity. All rights reserved. No reuse allowed without permission.
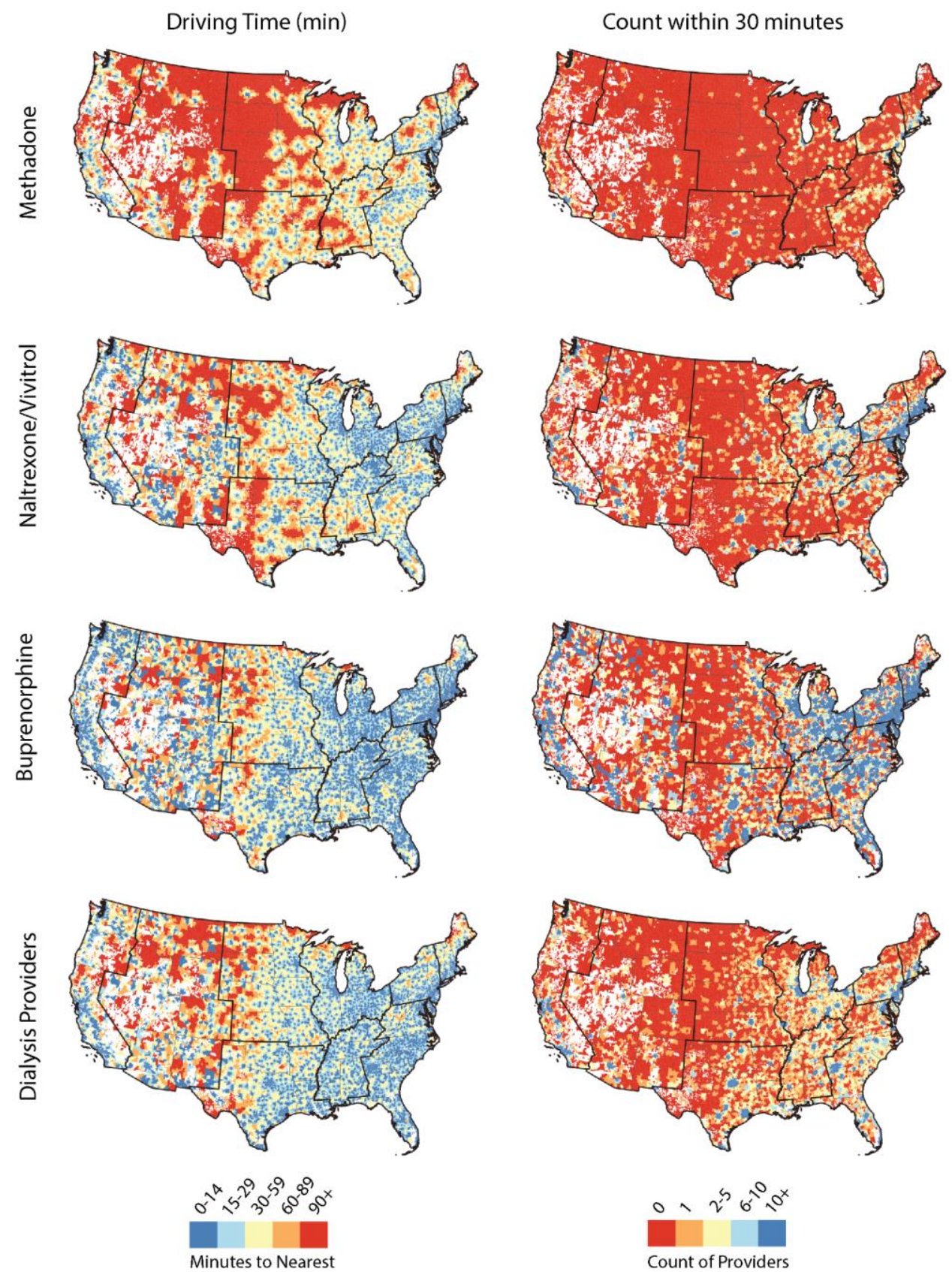

Exhibit 2. Driving time to the nearest MOUD resource (buprenorphine, extended-release naltrexone, methadone, and dialysis center) and count of resources within 30 minutes driving time in the continental US in 2020 with Census Regions bolded. Driving time map breaks were derived based on using 90 minutes as a conservative benchmark for the highest threshold (lowest level of access) for reaching MOUD providers. Based on existing access literature, map breaks were chosen to show variation of accessibility within 15 minutes, 30 minutes (benchmark of accessibility in existing dialysis literature), 60 minutes, 90 minutes, and greater than 90 minutes. 


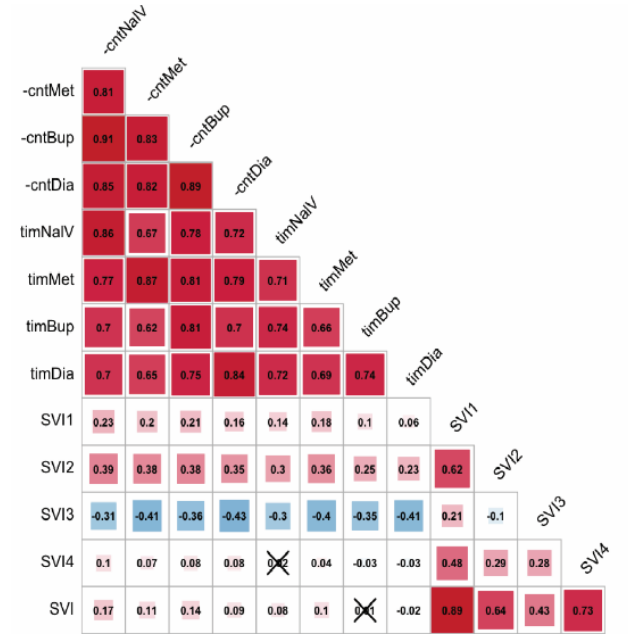

All Continental U.S. ZCTAs $(n=32,584)$$$
\begin{array}{ll|l}
\hline \text {-cntBup } & 0.82 & 0.63 \\
\hline \text { s. }
\end{array}
$$

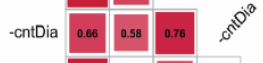

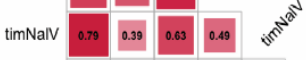$$
\begin{array}{l|l|l|l|l|l|l|l|l|l|l|l|}
\text { timMet } & 0.55 & 0.8 & 0.62 & 0.57 & 0.45 \\
\hline
\end{array}
$$

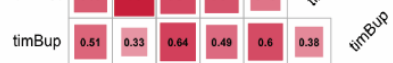

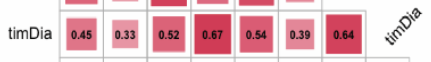

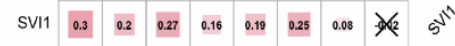

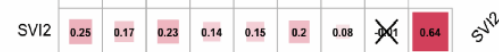

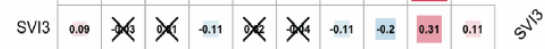$$
\begin{array}{l|l|l|l|l|l|l|l|l|l|l|l|l|l|l|l|l}
\text { SV14 } & 0.16 & 0.13 & 0.13 & 0.09 & \chi & 0.15 & -0.09 & 0.16 & 0.49 & 0.36 & 0.34 & 5^{50}
\end{array}
$$$$
\begin{array}{l|l|l|l|l|l|l|l|l|l|l|l|l|}
\text { SVI } & 0.29 & 0.18 & 0.24 & 0.12 & 0.15 & 0.22 & X & 0.1 & 0.89 & 0.7 & 0.51 & 0.75 \\
\hline
\end{array}
$$

All Suburban ZCTAs $(n=8,067)$

$$
\text { -cntMet } 0.59
$$

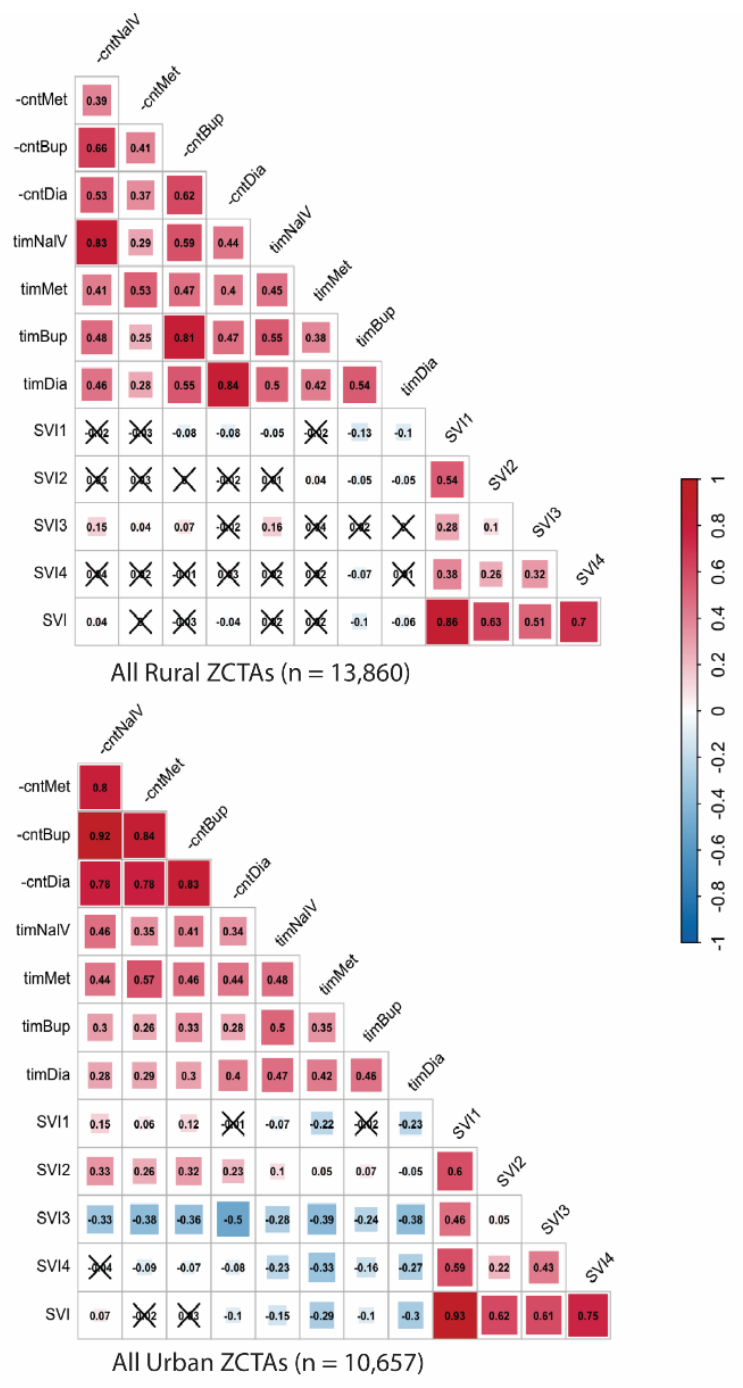

Exhibit 3. Correlation between social vulnerability and access to medications for opioid use disorder and dialysis centers in the continental US in 2020. The shading depends on the magnitude of correlation coefficient, with red indicating positive correlations and blue indicating negative correlations. 
Exhibit 4. Summary Statistics of Driving Time Access Metrics across SVI Themes

Median Drive Time to the Nearest Methadone, Buprenorphine, and Naltrexone

\begin{tabular}{|c|c|c|c|c|c|c|c|c|c|c|c|c|c|}
\hline \multicolumn{2}{|l|}{ SVI Theme } & \multicolumn{4}{|c|}{ Rural } & \multicolumn{4}{|c|}{ Suburban } & \multicolumn{4}{|c|}{ Urban } \\
\hline Increasing vulnerability & Quar. & Met & $\mathrm{Nal}$ & Dial & Bup & Met & $\mathrm{Nal}$ & Dial & Bup & Met & $\mathrm{Nal}$ & Dial & Bup \\
\hline \multirow{4}{*}{$\begin{array}{l}\text { Socioeconomic } \\
\text { Vulnerability } \\
\text { (SVI Theme 1) }\end{array}$} & 1 & 60 & 40 & 35 & 31 & 32 & 22 & 22 & 18 & 15 & 8 & 8 & 0 \\
\hline & 2 & 65 & 39 & 35 & 29 & 36 & 23 & 23 & 19 & 13 & 7 & 6 & 0 \\
\hline & 3 & 62 & 36 & 32 & 26 & 42 & 25 & 21 & 19 & 12 & 6 & 5 & 0 \\
\hline & 4 & 61 & 38 & 31 & 25 & 47 & 32 & 23 & 22 & 9 & 6 & 4 & 0 \\
\hline \multirow{4}{*}{$\begin{array}{l}\text { Household } \\
\text { Composition \& } \\
\text { Disability } \\
\text { (SVI Theme 2) }\end{array}$} & 1 & 57 & 36 & 33 & 27 & 33 & 21 & 22 & 17 & 12 & 6 & 7 & 0 \\
\hline & 2 & 62 & 39 & 34 & 29 & 37 & 24 & 23 & 19 & 13 & 7 & 6 & 0 \\
\hline & 3 & 63 & 37 & 33 & 28 & 40 & 26 & 22 & 20 & 13 & 8 & 6 & 0 \\
\hline & 4 & 63 & 39 & 32 & 27 & 45 & 29 & 23 & 21 & 12 & 8 & 6 & 0 \\
\hline \multirow{4}{*}{$\begin{array}{l}\text { Minority Status \& } \\
\text { Language } \\
\text { (SVI Theme 3) }\end{array}$} & 1 & 61 & 34 & 33 & 27 & 40 & 25 & 24 & 21 & 21 & 14 & 14 & 9 \\
\hline & 2 & 61 & 37 & 32 & 27 & 38 & 24 & 23 & 19 & 18 & 11 & 11 & 3 \\
\hline & 3 & 63 & 43 & 32 & 27 & 38 & 26 & 20 & 18 & 14 & 7 & 7 & 0 \\
\hline & 4 & 64 & 49 & 35 & 30 & 38 & 28 & 19 & 17 & 10 & 5 & 4 & 0 \\
\hline \multirow{4}{*}{$\begin{array}{l}\text { Housing Type } \& \\
\text { Transportation } \\
\text { (SVI Theme 4) }\end{array}$} & 1 & 61 & 36 & 32 & 28 & 35 & 24 & 24 & 20 & 17 & 10 & 9 & 0 \\
\hline & 2 & 61 & 37 & 32 & 28 & 38 & 25 & 23 & 20 & 14 & 7 & 7 & 0 \\
\hline & 3 & 62 & 39 & 33 & 28 & 40 & 25 & 21 & 19 & 11 & 5 & 4 & 0 \\
\hline & 4 & 63 & 39 & 34 & 26 & 45 & 26 & 19 & 16 & 8 & 4 & 4 & 0 \\
\hline
\end{tabular}


medRxiv preprint doi: https://doi.org/10.1101/2021.09.30.21264351; this version posted October 1, 2021. The copyright holder for this preprint (which was not certified by peer review) is the author/funder, who has granted medRxiv a license to display the preprint in perpetuity.

All rights reserved. No reuse allowed without permission.

Source: We obtained 2018 Census tract social vulnerability index (SVI) data from Centers for Disease Control and Prevention.

\section{Appendix Exhibit 1.}

\begin{tabular}{l|llll}
\hline & Total & Urban & Suburban & Rural \\
\hline Naltrexone & 9,103 & 7,004 & 1,277 & 820 \\
Methadone & 1,442 & 1,254 & 145 & 43 \\
Buprenorphine & 51,191 & 42,784 & 5,229 & 3,163 \\
Dialysis & 7,724 & 5,828 & 1,174 & 656 \\
ZCTA* & 32,584 & 10,657 & 8,067 & 13,860 \\
Population & $320,026,981$ & $240,888,576$ & $47,938,471$ & $31,199,934$ \\
Population 18-64 & $198,264,579$ & $151,041,785$ & $28,976,347$ & $18,246,447$ \\
\hline
\end{tabular}

* All ZCTAs were used for access metric calculation, however, not all ZCTAs are included in the USDA RUCA dataset. Specifically, 20 ZCTAs are missing from the USDA zip code RUCA codes. $0.119 \%$ of MOUD and dialysis resources are located in these 20 ZCTAs, thus they were not assigned to any RUCA classification. These include 2 out of 9,103 Naltrexone locations, 15 out of 51,191 Buprenorphine locations and 66 out of 7724 Dialysis locations. 
medRxiv preprint doi: https://doi.org/10.1101/2021.09.30.21264351; this version posted October 1, 2021. The copyright holder for this preprint (which was not certified by peer review) is the author/funder, who has granted medRxiv a license to display the preprint in perpetuity. All rights reserved. No reuse allowed without permission.

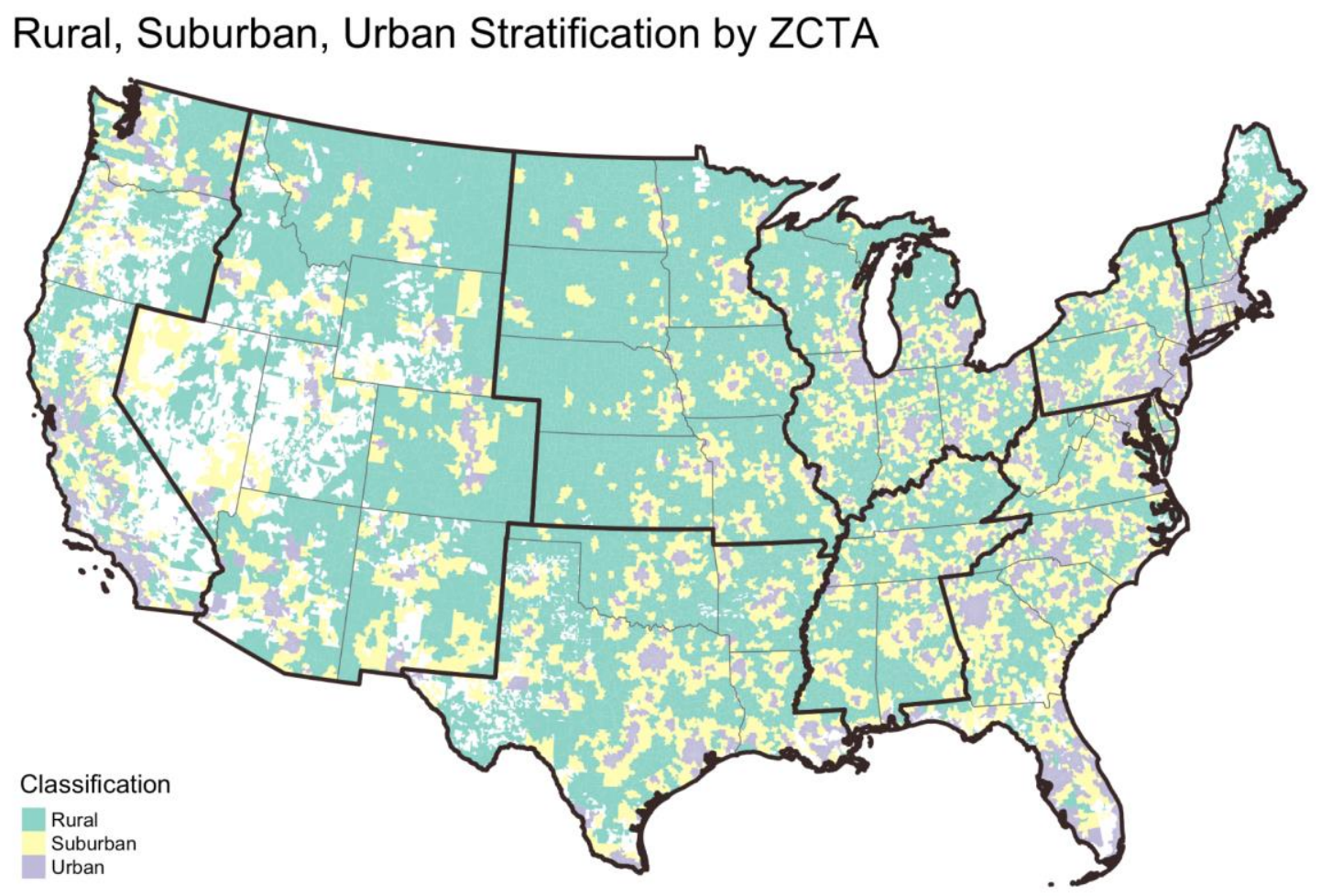

Appendix Exhibit 2. All assigned ZIP Code Tract Areas (ZCTA) in the continental US classified as rural, suburban, or urban, developed based on the U.S. Office of Management and Budget (OMB) RUCA Codes. 
Appendix Exhibit 3.

\begin{tabular}{|c|c|c|c|c|c|c|}
\hline Variable & $\mathbf{N}$ & $\begin{array}{c}\text { Overall, } \mathrm{N}= \\
32,584^{1}\end{array}$ & $\begin{array}{c}\text { Rural, } N= \\
13,860^{1}\end{array}$ & $\begin{array}{c}\text { Suburban, } N= \\
8,067^{1}\end{array}$ & $\begin{array}{c}\text { Urban, } N= \\
10,657^{1}\end{array}$ & $p$-value ${ }^{2}$ \\
\hline SVI1: Socioeconomic Status & 32,448 & 0.50 & 0.55 & 0.51 & 0.41 & $<0.001$ \\
\hline SVI2: Household Composition \& Disability & 32,475 & 0.59 & 0.67 & 0.61 & 0.42 & $<0.001$ \\
\hline SVI3: Minority Status \& Language & 32,477 & 0.27 & 0.18 & 0.20 & 0.49 & $<0.001$ \\
\hline SVI4: Housing Type \& Transportation & 32,471 & 0.50 & 0.54 & 0.46 & 0.48 & $<0.001$ \\
\hline Overall SVI & 32,445 & 0.47 & 0.51 & 0.45 & 0.42 & $<0.001$ \\
\hline
\end{tabular}

${ }^{1}$ Median

${ }^{2}$ Kruskal-Wallis rank sum test 
medRxiv preprint doi: https://doi.org/10.1101/2021.09.30.21264351; this version posted October 1, 2021. The copyright holder for this preprint (which was not certified by peer review) is the author/funder, who has granted medRxiv a license to display the preprint in perpetuity. All rights reserved. No reuse allowed without permission.

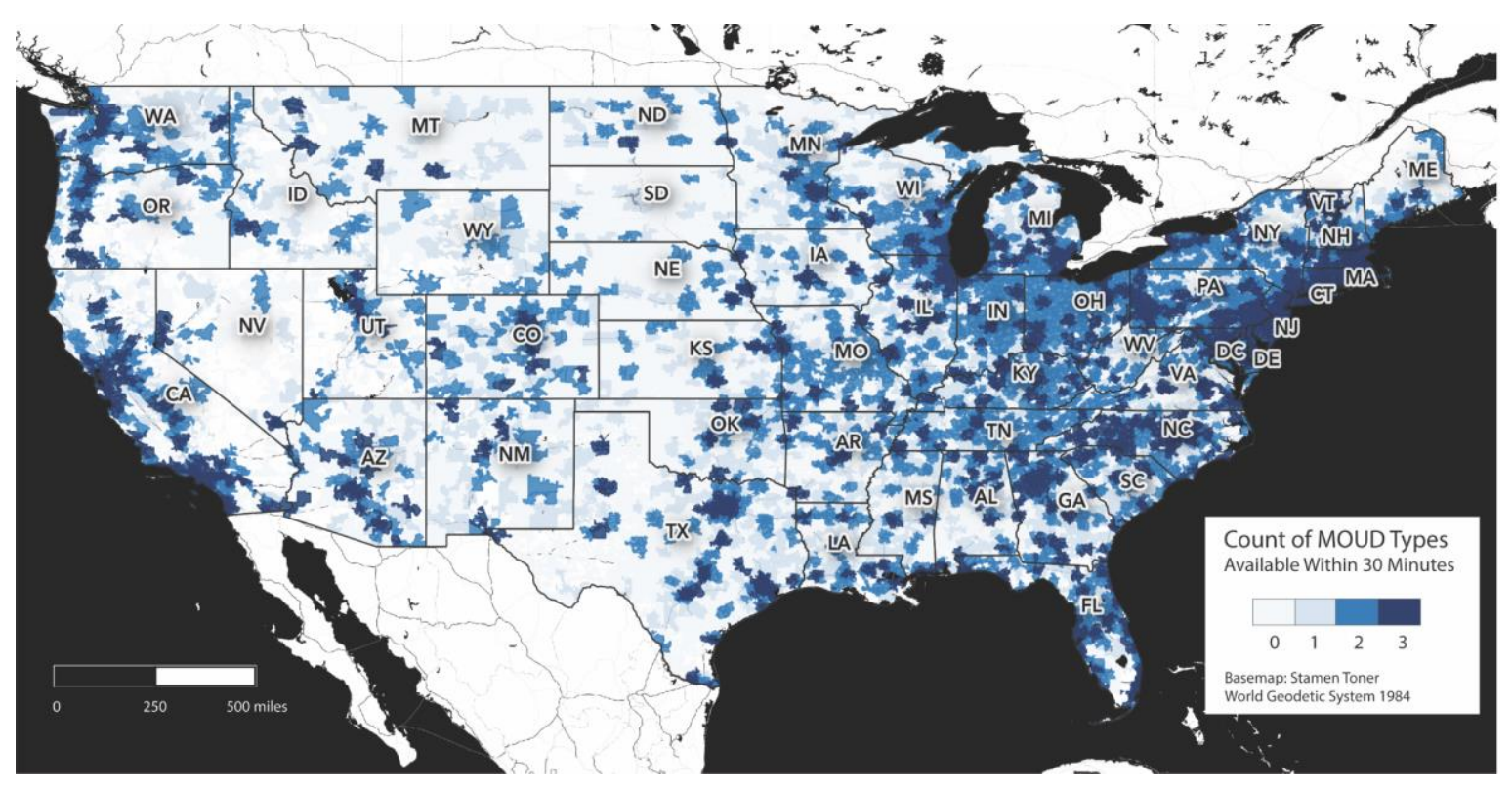

Appendix Exhibit 4. Count of MOUD types within 30 minutes driving time of every population-weighted ZCTA centroid in the continental US. 